\title{
Boas práticas em partos domiciliares: perspectiva de mulheres que tiveram experiência de parto em casa
}

Clara Fróes de Oliveira Sanfelice ${ }^{1}$, Antonieta Keiko Kakuda Shimo ${ }^{2}$

\footnotetext{
${ }^{1}$ Enfermeira, Doutora em Enfermagem. Enfermeira do Centro Obstétrico do Hospital da Mulher Prof. Dr. José Aristodemo Pinotti da Universidade Estadual de Campinas. Campinas, SP, Brasil. E-mail: c023389@dac.unicamp.br.

${ }^{2}$ Enfermeira, Doutora em Enfermagem. Professora Doutora da Faculdade de Enfermagem da Universidade Estadual de Campinas. Campinas, SP, Brasil. E-mail: akkshimo@unicamp.br.
}

Recebido: 18/08/2014.

Aceito: 22/09/2015.

Publicado: 30/06/2016

Como citar esse artigo:

Sanfelice CFO, Shimo AKK. Boas práticas em partos domiciliares: perspectiva de mulheres que tiveram experiência de parto em casa. Rev. Eletr. Enf. [Internet]. 2016 [acesso em:_____];18:e1159. Disponível em: http://dx.doi.org/10.5216/ree.v18.31494.

\begin{abstract}
RESUMO
Pesquisa de abordagem qualitativa, exploratória e descritiva cujo objetivo foi identificar as boas práticas de partos domiciliares na perspectiva de mulheres que pariram em casa. Os dados foram colhidos por meio de entrevistas semiestruturadas, aplicadas em 2014, audiogravadas e imediatamente transcritas. A amostra foi composta por 14 mulheres que tiveram uma experiência de parto em casa, planejado e assistido, na cidade de Campinas-SP e região. As falas foram analisadas segundo o método de análise de conteúdo de Bardin. Os resultados originaram quatro categorias emergentes: estrutura ambiental favorável; liberdade de escolhas; apoio e suporte emocional; e comprometimento da equipe de saúde. Tais achados sugerem que os profissionais que prestam assistência à parturiente, tanto no modelo de atendimento domiciliar como no hospitalar, valorizam esses aspectos buscando melhorias na qualidade da assistência. Lacunas relacionadas à satisfação das mulheres, aspectos positivos da experiência, dificuldades vivenciadas, desfechos obstétricos e neonatais indicam possibilidades para novos estudos.

Descritores: Parto Humanizado; Enfermagem Obstétrica; Parto Domiciliar.
\end{abstract}

\section{INTRODUÇÃO}

O atual modelo de atenção ao parto no Brasil é caracterizado pelo atendimento predominantemente institucionalizado, excessivamente medicalizado, aliado a elevados índices de cirurgia cesariana e uso indiscriminado da tecnologia e de intervenções rotineiras sem respaldo científico ${ }^{(1)}$. 
Segundo as estatísticas atuais, pouco mais de $98 \%$ dos nascimentos do país ocorrem dentro de instituições de saúde ${ }^{(2)}$. Embora o senso comum considere o parto institucionalizado como sinônimo de segurança, um crescente volume de pesquisas sobre as experiências das mulheres durante a gravidez e em particular no parto, têm demonstrado um quadro perturbador, caracterizado por abusos, desrespeito, maustratos e negligência durante a assistência ao parto nas instituições de saúde ${ }^{(3)}$.

Diante desse cenário, observa-se um movimento de procura à prática do parto planejado em domicílio, especialmente nos grandes centros urbanos, mesmo onde o acesso a serviços de saúde está disponível, por mulheres que se mostram profundamente descontentes com o modelo atual, que buscam e se cercam de informação de qualidade para Ihes respaldarem, vão às ruas reivindicar práticas baseadas em evidências e denunciar a violência obstétrica sofrida e ainda presente na maioria das instituições de saúde ${ }^{(4)}$.

A literatura científica internacional compila estudos cuja temática é a seguridade e os resultados obstétricos e neonatais dos partos domiciliares ${ }^{(5-7)}$, com destaque para o recente estudo norte americano realizado com uma coorte de 16.924 mulheres em gestação de risco habitual que planejavam parir em casa, acompanhadas no período de 2004 a 2009. O estudo apresentou significativa taxa de parto natural (93,6\%), sem aumento dos resultados adversos para mãe e bebê( $\hat{~}^{(8)}$.

As publicações nacionais apontam resultados favoráveis ao parto domiciliar, tais como reduzida taxa de transferência hospitalar, de cirurgia cesariana, de traumas perineais e uso de fármacos tanto no trabalho de parto como no pós-parto, bem como altas porcentagens de posições verticalizadas durante o trabalho de parto e parto, contato pele a pele e amamentação na primeira hora de vida ${ }^{(9-10)}$.

A prática de parir em casa tem sido relacionada ao nível de escolaridade mais alto, possivelmente devido à facilidade de acesso à informação e ao conhecimento em saúde permitindo análise crítica às práticas obstétricas e possibilidade de argumentação e sustentação da decisão pelo parto domiciliar ${ }^{(11)}$. Aliado e esses fatores, parir em casa parece ser uma forma de reação à violência institucional, à fragmentação e a despersonalização da assistência hospitalar ${ }^{(4)}$.

Munidas de informação, as mulheres que desejam um parto domiciliar buscam uma assistência obstétrica fundamentada em evidências científicas. Dessa forma, essa pesquisa buscou identificar quais são as boas práticas que fazem parte da assistência ao parto em domicílio na voz de mulheres que tiveram o parto em casa.

\section{MÉTODOS}

Estudo exploratório, descritivo e de abordagem qualitativa, realizado com 14 mulheres que pariram em casa de forma assistida e planejada, no ano de 2014, na cidade de Campinas-SP e região.

Os critérios para inclusão das mulheres no estudo foram: ser maior de 18 anos; ter vivenciado ao menos um parto domiciliar assistido por profissional habilitado e planejado e; estar entre três e seis meses de pós-parto. A definição do número de participantes atendeu ao critério de amostragem por saturação, definido como a suspensão de inclusão de novos participantes quando os dados obtidos passam a 
apresentar, na avaliação do pesquisador, certa redundância ou repetição, não sendo considerado relevante persistir na coleta. Esse conceito tem sido amplamente utilizado nas pesquisas qualitativas na área da saúde ${ }^{(12)}$.

Os dados foram coletados por meio de um instrumento composto por caracterização sociodemográfica e obstétrica, juntamente com uma entrevista semiestruturada composta por três questões abertas. As entrevistas foram audiogravadas e imediatamente transcritas, tiveram duração média de 25 minutos e foram realizadas no domicílio das mulheres. Todas as participantes assinaram o TCLE antes de iniciar a entrevista.

O tratamento e análise dos dados ocorreu através do processo de análise de conteúdo proposta por Bardin (1977), o qual é composto por três etapas: 1) pré-análise; 2) exploração do material e 3) tratamento dos resultados, inferência e interpretação ${ }^{(13)}$.

A partir dos depoimentos, buscou-se descobrir as unidades de sentido, que posteriormente foram separadas em subcategorias e, em seguida, agrupadas em quatro categorias temáticas para análise: 1) estrutura ambiental favorável; 2) liberdade de escolhas; 3) apoio emocional e 4) comprometimento da equipe de saúde.

Para se garantir o sigilo e a confidencialidade dos relatos, as participantes foram identificadas por codinomes que se referem à mitologia greco-romana.

A condução do estudo está fundamentada nas diretrizes nacionais para pesquisas com seres humanos, tendo sido aprovado no Comitê de Ética em Pesquisa da Faculdade de Ciências Médicas da Universidade Estadual de Campinas/Unicamp, com protocolo de no 331.743.

\section{RESULTADOS}

\section{Caracterização sociodemográfica}

A faixa etária das mulheres variou de 25 a 39 anos, com predomínio do intervalo entre 25-29 anos de idade. Das 14 participantes, todas possuíam ensino superior completo e eram casadas ou encontravam-se em união estável. Dentre elas, 13 possuíam convênio médico, 11 relataram exercer alguma atividade remunerada e sete possuíam renda familiar maior ou igual a 10 salários mínimos ${ }^{1}$.

Em relação aos dados obstétricos, oito eram nulíparas e dentre as multíparas $(n=6)$, cinco tiveram um parto vaginal e hospitalar anterior à experiência do parto domiciliar.

As categorias encontradas estão apresentadas, em forma de diagrama, na Figura 1.

\footnotetext{
${ }^{1}$ Salário mínimo de referência para o ano de $2014=$ R\$ 724,00. 


\section{Boas práticas de partos domiciliares}

Estrutura ambiental favorável
Liberdade de escolhas

Apoio emocional
Comprometimento da equipe de saúde

Figura 1: Diagrama de categorias. Campinas, SP, Brasil, 2016.

\section{DISCUSSÃO}

\section{Estrutura ambiental favorável}

A pesquisa evidenciou que a experiência do trabalho de parto e parto pode ser melhor vivenciada quando a mulher dispõe de um ambiente favorável para esse momento. Segundo as participantes dessa pesquisa, tecnologias não invasivas para alívio da dor, relacionadas à ambiência, tais como o uso da música, a imersão em água e a diminuição da luminosidade, repercutiram positivamente na experiência vivida, pois criam uma atmosfera acolhedora e propícia ao relaxamento.

(...) a água é muito importante, tem hora que só a água ajuda (...) música: eu fiz uma seleção, (...) tinha umas de relaxamento, mantra. Meia luz, nenhuma luz acesa, só abajur, velas. As massagens... (Hemera)).

A estrutura ambiental favorável também diz respeito ao acesso/disponibilidade aos métodos de alívio não farmacológicos para alívio das dores.

Uma recente revisão integrativa investigou o uso dos métodos não-farmacológicos para o alívio da dor durante o trabalho de parto normal apontando como mais utilizados a hidroterapia (banho de imersão ou aspersão); deambulação; exercícios de relaxamento e respiração, massagem, bola de parto (bola suíça), estimulação elétrica e crioterapia ${ }^{(14)}$.

(...) as meninas colocaram uma bolsa de água quente aqui [região lombar]. Isso foi fundamenta! Toda vez que tinha água quente dava uma alívio muito grande (...). A água ajuda bastante você a relaxar, então eu tomava um monte de banho. Eu ficava um tempão na banheira com água morna: eu acho que isso é muito importante (...). Ela passava um óleo nas costas, fazia massagem e... dava um alívio!... (Tessala).

O calor e a sensação de flutuação que ocorre quando a mulher entra na água aquecida ajudam a liberar a tensão muscular e podem conferir uma sensação de bem estar. Além disso, a estimulação nervosa da pele promove vasodilatação, reversão da resposta nervosa simpática e redução na produção de catecolaminas. Assim, as contrações são menos dolorosas quando a mulher está em contato com a água aquecida ${ }^{(15)}$. A banheira é uma coisa que muda a dimensão da concentração [consciência da dor]: onde estava doendo de um jeito, começa a doer de outro, mais suportável..., no final, foi essencial! (...) Você fica se preocupando menos em se segurar. Você não fica de pé, solta no ar. Você tem o apoio da água e isso dá uma sensação 
gostosa! (Latona).

(...) a questão da água foi muito importante; eu fui para o chuveiro. Já aliviou muito, mas ao entrar na piscina foi maravilhoso! Falei na hora: gente, toda mulher tinha que ter direito a isso! Porque dá um alívio muito bom, você consegue relaxar. (...) Em termos de coisas físicas, acho que foi um ponto diferencial no trabalho de parto (Perséfone).

A recente revisão sistemática da Biblioteca Cochrane indica que a imersão em água durante o primeiro período do trabalho de parto reduz significativamente o uso de analgesia farmacológica (peridural e raquianestesia), não está associado a nenhuma diferença quanto ao tipo de parto, ao índice de Apgar no 5o minuto, à infecção neonatal e à internação em unidades neonatais. Além disso, a imersão em água parece estar relacionada à diminuição da duração do primeiro estágio do trabalho de parto ${ }^{(16)}$.

A utilização da música durante o trabalho de parto é capaz de conferir diferentes efeitos, tais como o alívio da dor durante as contrações, auxílio na diminuição da tensão e do medo, ambientalização da paciente no hospital, estímulo à oração e à espiritualidade. Essas condições possibilitam que a parturiente experimente um estado de relaxamento mais eficaz no intervalo das contrações, levando a uma evolução mais amena e eutócica do trabalho de parto e elevando, na mulher, o limite de tolerância à dor e ao desconforto ${ }^{(17)}$. Assim, a utilização da musicoterapia se mostra um método promissor de manejo da dor que associado à medicina tradicional é capaz de reduzir a percepção da dor e a necessidade de recursos farmacológicos para aliviá-la ${ }^{(18)}$.

Assim, há de se considerar que a estrutura ambiental pode interferir positivamente no processo de parto e representar um elemento facilitador da assistência ao parto. Da mesma forma, a utilização dos métodos não farmacológicos para alívio das dores deve ser fortemente encorajada, tendo em vista tanto os bons resultados evidenciados cientificamente, como o baixo custo para sua execução e a fácil aplicabilidade dos mesmos.

\section{Liberdade de escolhas}

A liberdade de escolhas, facilitada no ambiente doméstico, se mostrou como outro importante aspecto do processo de parir em casa, na ótica das mulheres desse estudo. A parturiente se sente mais segura e confiante quando lhe é dada a possibilidade de escolher e participar dos procedimentos que envolvem o seu parto $^{(19)}$

(...) eu acho que essa liberdade de escolha de onde eu quero estar, qual a posição que quero, a liberdade de saber que você pode se expressar da maneira que for que ninguém vai ficar ofendido, ninguém vai mandar você ficar quieta, poder falar o que você quiser, agir da maneira que você quiser, se sentir livre mesmo, acho que isso ajuda bastante (Nice).

Uma maior escolaridade das mulheres que optam pelo parto domiciliar está relacionada a maior facilidade de acesso à informação e ao conhecimento biomédico ${ }^{(11)}$. Quando a mulher se encontra 
devidamente informada, se torna capaz de julgar criticamente suas opções e escolher conscientemente. Estimular as mulheres à tomada de decisão informada é valorizar sua capacidade de decidir; respeitar o direito ao próprio corpo e à autonomia; promover o direito à condição de pessoa e resgatar o cuidado centrado nas suas necessidades ${ }^{(20)}$.

A postura adotada pela equipe de saúde no ambiente doméstico estimula o exercício da autonomia e do protagonismo materno. Defender a autonomia do usuário é reconhecer sua voz ativa no processo terapêutico. É reconhecer que ele tem necessidades, valores, expectativas e desejos, frutos da sua natureza e cultura, que precisam ser considerados no cuidado em saúde ${ }^{(21)}$.

Ao se apropriarem da informação, até então monopolizada pelo médico, as usuárias relativizam a autoridade do profissional ao mesmo tempo em que afirmam sua insatisfação com o que é oferecido, reinterpretam sua experiência, denunciam violência a que se sentem submetidas, e reivindicam seu direito tanto de escolha como de recusa informada ${ }^{(22)}$.

É importante ressaltar que a democratização das relações entre profissionais de saúde e usuários, em um modelo de corresponsabilidade, além de valorizar a autonomia do usuário em relação à escolha da terapêutica e dos procedimentos está associada a melhores resultados em saúde ${ }^{(21)}$.

Não permitir, coibir ou debochar da livre expressão e do comportamento de uma mulher em trabalho de parto é considerado como um ato de violência obstétrica na atualidade e dificilmente se dá dentro do ambiente doméstico, já que, nesse espaço, a filosofia do atendimento está alicerçada no protagonismo feminino e é sustentada por uma diferente concepção do nascer e parir.

(...) essa liberdade de você se alimentar, de você tomar líquidos, o que você quer, não o que te obrigam... Nossa! achei isso muito importante! (Perséfone).

Infelizmente a grande maioria das instituições de saúde não permite que as parturientes comam e bebam nesse período, ainda que a literatura científica atual aponte que não há justificativa para se restringir a alimentação e a hidratação para as mulheres de baixo risco em trabalho de parto. Essas, dentre tantas outras restrições impostas no ambiente hospitalar estão sendo cada vez mais questionadas pela sociedade em virtude da ampla disseminação do conhecimento científico atual que, por sua vez, preconiza práticas contrárias ao que o sistema vigente impõe para a assistência durante o trabalho de parto e parto.

O acesso à informação científica amplifica a insatisfação das mulheres no que se refere ao atual modelo de atendimento ao parto, uma vez que lhes permite perceber que profissionais e instituições de saúde nem sempre empreendem mudanças relacionadas a esse tipo de assistência, e que continuam acreditando na segurança e eficácia das práticas não recomendadas ou dos procedimentos potencialmente prejudiciais $^{(23)}$.

Diante desse cenário, percebe-se que as mulheres querem ser ouvidas; querem, e têm o direito, de participarem das escolhas e das decisões sobre seus corpos e partos. Essa postura se apresenta como natural no ambiente doméstico, sendo valorizada pelos profissionais que nele atendem. No entanto, considera-se 
que a obstetrícia contemporânea precisa incluir as diferentes (e necessárias) relações de corresponsabilidade entre profissionais e usuárias ${ }^{(24)}$, independente do ambiente de parto.

\section{Apoio e suporte emocional}

As participantes desta pesquisa manifestaram-se, com grande convicção, quanto a importância do apoio e do suporte emocional oferecido, tanto pelo companheiro, quanto pela doula, durante o processo de parto e nascimento, corroborando os achados em estudos nacionais e internacionais ${ }^{(19,25)}$.

A oportunidade de escolher seu acompanhante foi tópico relatado como elemento de satisfação e de produção da tranquilidade, necessária e positiva para o nascimento do seu filho ${ }^{(19)}$. A presença de acompanhante promove confiança e segurança no momento do parto, além de ser uma fonte de apoio e força, capaz de amenizar a dor e a sensação de solidão além de gerar bem-estar emocional e físico ${ }^{(25)}$.

A inclusão do acompanhante de parto e/ou da doula é tão relevante quando se estuda o modelo de atenção ao parto preconizado na atualidade que foi tema de uma das mais recentes revisões da Biblioteca Cochrane, na área de obstetrícia. Em tal revisão aponta-se que mulheres apoiadas continuamente no período intraparto tiveram menor tendência de necessitar de analgesia, de cesárea e de relatar insatisfação com a experiência do parto. Assim, os revisores concluem de forma categórica que todas as mulheres devem ter apoio de profissional dos serviços, da doula e/ou do acompanhante durante o trabalho de parto ${ }^{(24)}$.

(...) foi muito importante, porque ele fez parte de verdade, ele estava junto, ele fez força junto (...) Eu tava fazendo força, ele também. Foi uma coisa assim: ele entrou junto, ele pariu junto e para o homem é super difícil. É muito importante para a mulher, esse movimento do pai... (Hemera).

Teve a intervenção da doula, intervenção no sentido de puxar [incentivar](...) não tô dando conta! sim, está dando! $O$ apoio dela foi super importante! (llitia).

Daí a importância de fortalecer a introdução na cena de atenção ao parto de uma doula, de escolha da mulher, como elemento de observação, apoio e segurança.

Embora no ambiente domiciliar a mulher tenha a possibilidade de escolher quantas e quais pessoas estarão ao seu lado no momento do parto, na maioria das vezes isso não é possível no ambiente hospitalar. Levando em consideração a questão do acompanhante (que não se trata da doula), essa pesquisa reforça os benefícios de sua permanência e representa mais um incentivo ao cumprimento da Lei do Acompanhante (Lei n. 11.108) dentro das instituições de saúde.

\section{Comprometimento da equipe de saúde}

As participantes desse estudo relataram que uma equipe de saúde que se mostra comprometida com o atendimento representa um fator fundamental para o enfrentamento da experiência do parto em casa.

O estabelecimento de uma relação de confiança com os profissionais de saúde fortalece sentimentos positivos que tranquilizam a parturiente. Quando esse relacionamento não é efetivado, a experiência do 
parto é afetada de forma negativa ${ }^{(19)}$.

(...) eu sinto muito confiança! (...) Para mim isso foi o melhor: (...) esse carinho, de ter pessoas que estão ali presentes, (...) é isso que é o mais difícil para o obstetra! Eu acho que a coisa mais importante do parto é que quem esteja, esteja ali, entregue na coisa. E você sente (a parturiente sente) quando você está ali, mas tá olhando o celular, mas tem que sair... Eu acho que isso deve ser um estresse do cão, entendeu? Então eu acho que a coisa mais importante é que quem esteja, realmente esteja (Selene).

A voz dessa participante remete à importância e o impacto que um acompanhamento individualizado e atencioso pode causar sobre a evolução do trabalho e parto. Oferecer um cuidado personalizado, atentando para os sinais que a mulher apresenta, seus desejos e insatisfações, incluindo também sua família no processo, promove bem-estar e conforto para os envolvidos. Isso facilita o trabalho da equipe, pois, quando a relação está pautada na confiança e segurança previamente estabelecidas, é possível realizar um parto envolto em uma esfera de cuidado, tranquilidade e amor ${ }^{(19)}$.

Estar rodeada de pessoas de confiança, sejam acompanhantes ou profissionais comprometidos com o processo do parto, influencia na percepção a respeito do ambiente, tornando-o mais íntimo. Essa proximidade, aliada a um ambiente calmo, proporciona segurança e bem-estar à parturiente. Tais fatores podem, muitas vezes, passar desapercebidos, no entanto, são integrantes do cuidado e conforto indispensáveis no decorrer do trabalho de parto e parto ${ }^{(19)}$ e parecem ser potentes o suficiente para modificar positivamente essa experiência.

\section{CONCLUSÕES}

Essa pesquisa permitiu identificar boas práticas presentes nos partos domiciliares relativas à estrutura ambiental favorável, à liberdade de escolhas, ao apoio emocional e ao comprometimento da equipe de saúde envolvida.

As práticas descritas nessa pesquisa encontram respaldo na literatura científica atual e, portanto, devem ser foco de atenção para profissionais diretamente envolvidos no parto e nascimento tais como médicos, enfermeiras obstetras, obstetrizes e doulas. Por se tratar de práticas cujos efeitos beneficiam a população, serem de baixo custo e de fácil aplicabilidade, sugerem-se esforços para que sejam implantadas no modelo de atendimento hospitalar.

As análises realizadas a partir dos pensamentos capturados mostram que as mulheres estão clamando por respeito à sua individualidade, aos seus corpos e à fisiologia do parir e nascer, intrínseca a cada uma. Almejam um parto amoroso e acolhedor, com a participação de pessoas de sua escolha que as estimulem e encorajem às boas práticas. Desejam estabelecer relações democráticas com profissionais de saúde no que tange às decisões que as envolvem; querem ser ouvidas e respeitadas enquanto sujeitos ativos e conscientes e anseiam por autonomia sobre suas experiências de parto.

Por se tratar de uma modalidade de atendimento incipiente no modelo de atendimento obstétrico 
brasileiro, considera-se a necessidade de mais investigações sobre os diferentes aspectos que envolvem o parto domiciliar, tais como a satisfação das mulheres, pontos positivos da experiência, dificuldades vivenciadas, desfechos obstétricos e neonatais, entre outros, a fim de que tal prática tenha mais visibilidade no meio acadêmico e seja cada vez mais compreendida por toda a sociedade.

\section{REFERÊNCIAS}

1. Lessa HF, Tyrrell MAR, Alves VH, Rodrigues DP. Information for the option of planned home birth: women's right to choose. Texto Context - Enferm [Internet]. 2014 [acesso em: 30 jun. 2016];23(3):665-72. Disponível em:

http://dx.doi.org/10.1590/0104-07072014000930013.

2. Ministério da Saúde [Internet]. IDB 2012 Brasil. Indicadores de cobertura. TabNet Win32 3.0: F.7 Proporção de partos hospitalares. Brasília: Ministério da Saúde; 2012 [acesso em: 30 jun. 2016]. Disponível em: http://tabnet.datasus.gov.br/cgi/tabcgi.exe?idb2012/f07.def.

3. Organização Mundial da Saúde. Prevenção e eliminação de abusos, desrespeito e maus-tratos durante o parto em instituições de saúde [Internet]. Disponível em:

http://apps.who.int/iris/bitstream/10665/134588/3/WHO_RHR_14.23_por.pdf.

4. Sanfelice CFO, Shimo AKK. Home childbirth: progress or retrocession? Rev Gaucha Enferm [Internet]. 2014 [acesso em: 30 jun. 2016];35(1):157-60. Disponível em: http://dx.doi.org/10.1590/1983-1447.2014.01.41356.

5. Jonge A, Mesman JAJM, Mannien J, Zwart JJ, van Dillen J, van Roosmalen J. Severe adverse maternal outcomes among low risk women with planned home versus hospital births in the Netherlands: nationwide cohort study. BMJ [Internet]. 2013 [acesso em: 30 jun. 2016];346:f3263. Disponível em: http://dx.doi.org/10.1136/bmj.f3263.

6. Birthplace in England Collaborative Group. Perinatal and maternal outcomes by planned place of birth for healthy women with low risk pregnancies: the Birthplace in England national prospective cohort study. BMJ [Internet]. 2011 [acesso em: 30 jun. 2016];343:d7400. Disponível em: http://dx.doi.org/10.1136/bmj.d7400.

7. Nove A, Berrington A, Matthews Z. Comparing the odds of postpartum haemorrhage in planned home birth against planned hospital birth: results of an observational study of over 500,000 maternities in the UK. BMC Pregnancy Childbirth [Internet]. 2012 [acesso em: 30 jun. 2016];12:130. Disponivel em: http://dx.doi.org/10.1186/1471-2393-12130 .

8. Cheyney M, Bovbjerg M, Everson C, Gordon W, Hannibal D, Vedam S. Outcomes of Care for 16,924 Planned Home Births in the United States: The Midwives Alliance of North America Statistics Project, 2004 to 2009. J Midwifery Womens Health [Internet]. 2014 [acesso em: 30 jun. 2016];59(1):17-27. Disponível em:

http://doi.wiley.com/10.1111/jmwh.12172.

9. Colacioppo P, Koiffman M, Riesco M, Schneck C, Osava R. Parto domiciliar planejado: resultados maternos e neonatais. Rev Enferm Ref [Internet]. 2010 [acesso em: 30 jun. 2016];III Série(2):81-90. Disponível em:

http://dx.doi.org/10.12707/RII0932.

10. Koettker JG, Brüggemann OM, Dufloth RM, Knobel R, Monticelli M. Outcomes of planned home birth assisted by nurses, from 2005 to 2009, in Florianópolis, Southern Brazil. Rev Saude Publica [Internet]. 2012 [acesso em: 30 jun. 2016];46(4):747-50. Disponível em: http://dx.doi.org/10.1590/\$0034-89102012005000051.

11. Feyer ISS, Monticelli M, Knobel R. Perfil de casais que optam pelo parto domiciliar assistido por enfermeiras obstétricas. Esc Anna Nery [Internet]. 2013 [acesso em: 30 jun. 2016];17(2):298-305. Disponível em:

http://dx.doi.org/10.1590/S1414-81452013000200014.

12. Fontanella BJB, Ricas J, Turato ER. Amostragem por saturação em pesquisas qualitativas em saúde: contribuições teóricas. Cad Saude Publica [Internet]. 2008 [acesso em: 30 jun. 2016];24(1):17-27. Disponível em:

http://dx.doi.org/10.1590/\$0102-311X2008000100003.

13. Bardin L. Análise de conteúdo. Reto LA, Pinheiro A, tradutores. Lisboa: Edições 70, 2002.

14. Silva DAO, Ramos MG, Jordão VRV, Silva RAR, Carvalho JBL, Costa MMN. Uso de métodos não farmacológicos para o alívio da dor durante o trabalho de parto normal: revisão integrativa. Rev. enferm. UFPE on line [Internet]. 2013 [acesso em: 30 jun. 2016];7(5):4161-70. Disponível em:

http://www.revista.ufpe.br/revistaenfermagem/index.php/revista/article/view/2582.

15. Ricci SS. Enfermagem materno-neonatal e saúde da mulher. 1ạ ed. Rio de Janeiro: Guanabara Koogan; 2008.

Rev. Eletr. Enf. [Internet]. 2016 [acesso em:___/_];18:e1159. Disponível em: http://dx.doi.org/10.5216/ree.v18.31494. 
16. Cluett ER, Burns E. Immersion in water in labour and birth. In: Cluett ER, editor. Cochrane Database of Systematic Reviews [Internet]. Chichester, UK: John Wiley \& Sons, Ltd; 2009 [acesso em: 30 jun. 2016]. Disponível em: http://doi.wiley.com/10.1002/14651858.CD000111.pub3.

17. Tabarro CS, Campos LB, Galli NO, Novo NF, Pereira VM. Efeito da música no trabalho de parto e no recém-nascido. Rev Esc Enferm USP [Internet]. 2010 [acesso em: 30 jun. 2016];44(2):445-52. Disponível em:

http://dx.doi.org/10.1590/S0080-62342010000200029.

18. Bernatzky G, Presch M, Anderson M, Panksepp J. Emotional foundations of music as a non-pharmacological pain management tool in modern medicine. Neurosci Biobehav Rev [Internet]. 2010 [acesso em: 30 jun. 2016];35(9):198999. Disponível em: http://dx.doi.org/10.1016/j.neubiorev.2011.06.005.

19. Frello AT, Carraro TE. Componentes do cuidado de enfermagem no processo de parto. Rev. Eletr. Enf. [Internet]. 2010 [acesso em: 30 jun. 2016];12(4):660-8. Disponível em: http://dx.doi.org/10.5216/ree.v12i4.7056.

20. Sodré TM, Merighi MAB. Escolha informada no parto: um pensar para o cuidado centrado nas necessidades da mulher. Ciênc. cuid. saúde [Internet]. 2012 [acesso em: 30 jun. 2016];11(supl.):115-20. Disponível em:

http://dx.doi.org/10.4025/cienccuidsaude.v11i5.17062,

21. Soares JCRS, Camargo Jr KR. A autonomia do paciente no processo terapêutico como valor para a saúde. Interface - Comun Saúde, Educ [Internet]. 2007 [acesso em: 30 jun. 2016];11(21):65-78. Disponível em: http://dx.doi.org/10.1590/S1414-32832007000100007.

22. Salgado HDO, Niy DY, Diniz CSG. Groggy and with Tied Hands: The First Contact with the Newborn According to Women that Had an Unwanted C-Section. J Hum Growth Dev [Internet]. 2013 [acesso em: 30 jun. 2016];23(2):190-7. Disponível em: http://dx.doi.org/10.7322/jhgd.61298.

23. Leão MRC, Riesco MLG, Schneck CA, Angelo M. Reflexões sobre o excesso de cesarianas no Brasil e a autonomia das mulheres. Cien Saude Colet [Internet]. 2013 [acesso em: 30 jun. 2016];18(8):2395-400. Disponível em: http://dx.doi.org/10.1590/S1413-81232013000800024.

24. Diniz SG. O renascimento do parto, e o que o SUS tem a ver com isso. Interface - Comun Saúde, Educ [Internet]. 2014 [acesso em: 30 jun. 2016];18(48):217-20. Disponível em: http://dx.doi.org/10.1590/1807-57622013.0910. 25. Hodnett ED, Gates S, Hofmeyr GJ, Sakala C. Continuous support for women during childbirth. In: Hodnett ED, editor. Cochrane Database of Systematic Reviews [Internet]. Chichester, UK: John Wiley \& Sons, Ltd; 2013 [cited 2016 Jul 26]. Disponível em: http://doi.wiley.com/10.1002/14651858.CD003766.pub5. 